\title{
A Short Analysis of the Fundamental Issues in Language Teaching Research
}

\author{
Mohammad Zohrabi \\ English Department, Faculty of Literature, the University of Tabriz, Tabriz, Iran \\ Email: mohammadzohrabi@gmail.com
}

\begin{abstract}
The design that is selected for any study is like a skeleton which supports the different parts of the research. It is the research design which determines how the data should be collected, analyzed and interpreted. This article attempts to delineate the different research approaches: qualitative, quantitative and mixed methods design. At this juncture, the crucial issue is the gathering of information in order to get an understanding of the problem more deeply and find appropriate ways of dealing with it. Therefore, the data collection discusses the different types of data that should be obtained. After collecting the necessary data, the researcher should analyze them in detail. Thus, the data analysis is dealt at length. It is crucial that before carrying out the real study, the researcher ensure that the research design, data collection instruments and data analysis work well. Therefore, the pilot study comes to the aid of the researcher to help approach the actual phase of the research more confidently. Finally, every researcher should consider the rights of the participants and take heed of some rules during and after the research process. Therefore, the ethical issues explain how the researcher should act in conducting a study.
\end{abstract}

Index Terms — research design, data collection \& analysis, pilot study, ethical issues

\section{INTRODUCTION}

The researchers should choose an appropriate research design based on the objectives of the study. The design of the study has a crucial role because it glues the different parts of the research together. This article elaborates on five important points in any research endeavor: research design, data collection, data analysis, pilot study, and ethical issues. Clearly, conducting research requires some theoretical and practical knowledge. Also, every research design has its own particular rules and regulations. It is hoped that this article could give some useful insights to the postgraduate students and researchers who are about or intend to embark on conducting a study.

\section{RESEARCH DESIGN}

In the main, the vital aspect of any research process is the selection of an appropriate and pertinent research design. First, the design of the study is determined based on the problems that should be investigated. Second, it is selected based on the research questions and objectives. Burns (2000, p. 3) defines research as "a systematic investigation to find answers to a problem." More broadly, with regard to three approaches to research design (i.e. quantitative, qualitative, and mixed method), the factors that influence our choice include: "the research problem, the personal experiences of the researcher and the audience" (Creswell, 2003, p. 21). On the whole, language courses are dynamic entities and subject to change according to the ever changing needs and wants of the students. To this end, Alderson (1996, p. 292) holds that "designs for evaluation should be practical, realistic and flexible."

The determining factor in the choice of one design over another is the purpose of the inquiry. "The potential range of methods is large, but the important element here is to ensure that they are accessible and reproducible; selection of them will depend on purpose and point of application" (Murphy, 1985, p. 11). On the other hand, Brown (1989) emphasizes that selecting the research design depends on the evaluation dimensions. That is, whether our evaluation is summative and carried out at the end of the program or formative and performed during the lifetime of the course. Also, whether our emphasis is on the product and/or what the students have achieved or on the process of teaching-learning activities. Also, it should be clarified whether the research emphasis is more on the quantitative or qualitative data. It can be added that the research emphasis might be on both types of data at the same time. At this juncture, Blaxter et al. (2006) argue that if we could try to think methodologically on research design, the following questions might help illuminate our selection better. They (ibid., 62) argue that:

- What are the main purposes of your research?

- What is your role in the research?

- Do you think your values should affect research?

- Can you accommodate several methodologies in your research?

- Who are the audience for your research?

It can be concluded that factors affecting the choice of one approach over another include the objectives, researcher's experience, nature of the problem(s), audience, availability of the resources and facilities, availability of the budget and 
so on. Opting for a naturalistic and/or qualitative approach or a positivistic and/or experimental approach, Lynch (1996, p. 171) stresses "the inherent difficulties of trying to carry out experimental research in field settings, and of the limitations to what such an evaluation strategy can tell us about the programs we are investigating ..." He believes that applied linguistics is gradually distancing itself from the experimental methods and moving towards the naturalistic inquiries. Burns (2000, p. 3) also is of the opinion that since 1960s the gulf between "the scientific empirical tradition and the naturalistic phenomenological method" has deepened. However, he (ibid.) prefers a naturalistic approach and argues that "Social reality is regarded as a creation of individual consciousness, with meaning and the evaluation of events seen as a personal and subjective construction."

Most of the researchers prefer a mixed method (i.e. both quantitative and qualitative approaches) because of its advantages and flexibility. Lynch (1996, p. 171) states that "The preferred evaluation approach ... is mixed strategies (i.e. quantitative analysis of qualitative data) or mixed design (positivistic and naturalistic)." The mixed method easily allows the inquirer to collect both numerical data and text data. The researcher can use both types of data to increase the validity and reliability of his/her investigation. Creswell (2003, p. 22) also believes that "A mixed methods design is useful to capture the best of both quantitative and qualitative approaches." He maintains that in order to gain a better understanding of the problem "both closed-ended quantitative data and open-ended qualitative data prove advantages" (ibid.).

\section{DAta COLlection Design/SySTEM}

In order to conduct a research properly, the researcher should make every effort to choose a robust and adequate design based on the program's various stakeholders and his/her own objectives. To this end, a researcher can opt for a quantitative, qualitative or a mixed method design. Generally, Lynch (1996) refers to quantitative designs as positivistic research and to qualitative designs as naturalistic research.

\section{A. Quantitative Research}

Richards and Schmidt (2002, p. 436) state that quantitative research "uses procedures that gather data in numerical form ... [It] aims at causal explanation of phenomena through the identification of variables which can be made the basis of experimental investigation." In fact, quantitative research is called traditional approach because it was dominant in the 1960s and 1970s. In most cases the focus of attention is on the end product, i.e. the students' attainment of course objectives. Also, the research process merely consists of comparison of different teaching methods. Mainly, students are divided into two groups: control and experimental groups. The experimental group receives a treatment and the control group is taught through the regular program. A pretest and posttest is administered and the students' scores are studied accordingly. Alderson (1996, p. 283) confirms that "the results of such experimental methodologies were less than encouraging, and ... such approaches are inappropriate to program evaluation." In this regard, Long (1984) also disapproves of laboratory-like, experimental methods because of their lack of attention to the process of teachinglearning. That is, without the proper description of the process the product will be meaningless. At this juncture, Lynch (1996, p. 96) argues that "it is not enough simply show that a program was successful on some outcome measure. It must also be possible to make some judgments of what ... made the program successful." In the main, there are some differences between quantitative and qualitative researches. Blaxter et al. (2006, p. 65) mention some of these disparities as follows:

\section{Qualitative paradigms}

- Concerned with understanding behavior

from actors' own frames of reference

- Naturalistic and uncontrolled

observation

- Subjective

- Close to the data: the 'insider'

perspective

- Grounded, discovery oriented,

exploratory, expansionist,

descriptive, inductive

- Process-oriented

- Valid: real, rich, deep data

- Ungeneralizable: single case studies

- Holistic

- Assume a dynamic reality

Obviously, quantitative and/or positivistic research can hardly be of any use in a study. In any research endeavor there are various unexpected occurrences which the laboratory-like experimental designs cannot account for them. However, in the qualitative and/or naturalistic researches, the researcher takes part in the actual process of study and is always involved in the program rather than being an unknowledgeable outsider. In the naturalistic approaches the researcher usually does not disrupt the normal process of the classroom activities. Generally the qualitative approach is

\author{
Quantitative paradigms \\ - Seeks the facts/causes of social \\ phenomena \\ - Obtrusive and controlled \\ measurement \\ - Objective \\ - Removed from the data: the \\ 'outsider' perspective \\ - Ungrounded, verification oriented, \\ reductionist, hypothetico-deductive \\ - Outcome-oriented \\ - Reliable: hard \& replicable data \\ - Generalizable: multiple case studies \\ - Particularistic \\ - Assume a stable reality
}


exploratory in nature and does not attempt to verify predetermined hypotheses. Finally, the qualitative approaches presume that a program is a dynamic reality which changes over the time and is not stable.

\section{B. Qualitative Research}

The qualitative research allows the researcher to investigate the research setting, context and individuals' activities closely. This type of research attempts to study the participants and their performances in their natural milieu. For this reason, it is also referred to as naturalistic research. Therefore, the naturalistic research is heuristic with barely any predetermined questions or hypotheses to dictate the research process. Seliger and Shohamy contend that this approach is very useful when a researcher attempts to study the learning-teaching process in its natural setting. Blaxter et al. (2006, p. 64) elaborate on the qualitative research as follows:

Qualitative research... is concerned with collecting and analyzing information in as many forms, chiefly nonnumerical, as possible. It tends to focus on exploring, in as much detail as possible, small numbers of instances or examples which are seen as being interesting or illuminating, and aims to achieve depth rather than breath.

In this type of inquiry the researcher tries to focus on the specific context in which the research is being carried out and at the same time "collaborates with the participants" (Creswell, 2003, p. 19). The qualitative research is innovative as well as emergent and is concerned with individuals and their perceptions rather than with numbers and figures which are abstract and out of context. Lynch (1996, p. 14) insists that naturalistic paradigm "views the educational program being evaluated... as a process that is continuously changing rather than a stable, invariant treatment." Lynch also emphasizes that as more researchers use this approach in the field of English language teaching, therefore, the more sophisticated and elaborate ways of adapting its methodology to the particular context can be seen. By and large, the naturalistic approaches allow the researcher to collect data through different techniques such as observations, interviews, questionnaires, and field notes and also from various sources such as students, teachers, program staff and so on. Consequently, the variety of sources and techniques makes the data more valid and convincing.

\section{Qualitative vs. Quantitative Data}

In order to gather information, the researcher can opt either for qualitative or quantitative data. As usual, it depends on the purpose for which the research takes place. However, for any research to be rich and have convincing evidence, it is preferable that both types of data to be collected and used. The qualitative data can be described as the type of information which can be obtained through observations, interviews, open-ended questionnaires, field notes, and so on. Alderson (1996, p. 282) believes that exploring "attitudes and opinions are important to the evaluation." He then emphasizes that "observation, recording and interpretation of events, activities and feeling of participants" (ibid., 283) are also of paramount importance. In addition, Brown (1995, p. 227) assumes that the qualitative data contains "more holistic information ... that may not readily lend themselves to conversion into quantities or numbers." Nevertheless, Richards and Schmidt (2002, p. 435) assert that the qualitative data "can often be converted into quantitative form." On the whole, in order to interpret the qualitative data, the researcher can utilize them "in a principled and systematic manner [because] they are more important to actual decisions made in a program" (Brown, 1989, p. 232). In contrast, the quantitative data are countable pieces of information which are usually numerical in form. They can be obtained through "tests and objective-question questionnaire" (Dudley-Evans \& St John, 2000, p. 128).

Generally, a researcher might attempt to gather both the qualitative and quantitative information. The qualitative data are mostly obtained through observations, interviews and open-ended questionnaires and the quantitative data are gained through closed-ended questionnaires and tests. A researcher might not use testing procedures to collect data because as Elley (1989, p. 270) affirms "Samples are biased or unmatched... contamination occurs between experimental and control groups, and tests prove too difficult or too easy for students." Also, it can be stated that though tests may be important, "they are not the exclusive, or even the primary, focus of all evaluations" (Nunan, 1999, p. 190). Moreover, the information that can be gathered through tests has rather limited interpretational value because "They provide answers to what questions but cannot easily address the how or why" (Dudley-Evans \& St John, 2000, p. 128). More importantly, tests assess what teachers think are the objectives of the course, however, many vital and unexpected issues surface incidentally in the actual teaching-learning process. To this end, Slimani (1996, p. 199) reasons that: "However, since we are concerned with relating learning outcomes to their immediate and potentially determining environment, it appears rather difficult to think of ways of getting at learning evidence through testing and elicitation procedures as traditionally understood."

The main concern of any study is to obtain information that can modify the teaching and learning process. The crux of the matter is that students can somehow answer the questions on the exam paper. However, they can hardly perform this passive knowledge in listening, speaking, reading and writing. Therefore, the tests are the artificial way of measuring the students' knowledge which barely yield any valuable information about their real performance.

\section{SEARCHING FOR FACTS}

Naturally, the type of data that the researcher gathers almost entirely depends on the type of design that has been chosen. It is obvious that the most important step in any research process is the data collection procedure. If the aim of the research is to enquire about the students' achievements of course objectives then the researcher can gather data 
through the students' end-of-program tests. On the other hand, if the goal of the study is to improve the whole course, then the researcher can collect data through questionnaires, interviews, observations, course documents, and so on. However, the important point that the researcher should take care of is "the appropriate conduct of the data-gathering procedures" (Lynch, 1996, p. 7). Therefore, the researcher should decide on the pertinent types of data to be collected in order to make necessary interpretations according to them. As Murphy (1985, p. 15) stresses, we should "know what sort of information we want and the appropriate ways to choose from to get it." It can be concluded that the researcher should try to gather not only relevant data but also through suitable ways.

The main issue in the data collection process is the diversity of the information that is gathered. It is reasonable that the researcher attempt to gather as varied sorts of data as possible. Creswell (2003, p. 21) affirms that "collecting diverse types of data best provides an understanding of a research problem." Therefore, collecting more miscellaneous data increases the validity and consequently adds to the legitimacy and authenticity of the research endeavor. For instance, Nunan (1999, p. 189) argues that the researcher should also try to inquire into the "institutional facilities, the prevailing intellectual and emotional climate, relationships between administrative and teaching staff, and so on." To this end, Brown (1989, p. 233) proposes different ways of gathering data as follows:

TABLE 1.

EVALUATOR'S ROLE, CATEGORIES AND PROCEDURES

\begin{tabular}{|c|c|c|}
\hline Evaluator's role & Categories & Procedures \\
\hline \multirow[t]{2}{*}{ Out side looking in } & Existing information & $\begin{array}{l}\text { - Records analysis } \\
\text { - Systems analysis } \\
\text { - Literature review } \\
\text { - Letter writ ing }\end{array}$ \\
\hline & Observations & $\begin{array}{l}\text { - Case studies } \\
\text { - Diaries studies } \\
\text { - Behavior observation } \\
\text { - Interactional analysis } \\
\text { - Inventories }\end{array}$ \\
\hline \multirow[t]{3}{*}{$\begin{array}{l}\text { Facilitator drawing out } \\
\text { information }\end{array}$} & Interviews & $\begin{array}{l}\text { - Individual } \\
\text { - Group }\end{array}$ \\
\hline & Meetings & $\begin{array}{l}\text { - Delphi technique } \\
\text { - Advisory } \\
\text { - Interest group } \\
\text { - Review }\end{array}$ \\
\hline & Questionnaires & $\begin{array}{l}\text { - Biodata surveys } \\
\text { - Opinion surveys } \\
\text { - Self-rat ings } \\
\text { - Judgmental ratings } \\
\text { - Q sort }\end{array}$ \\
\hline
\end{tabular}

The list suggested by Brown (1989, p. 233) is rather comprehensive and detailed. However, a researcher cannot gather data through all these procedures because of the constraints of time, money and expertise. Brown (ibid.) himself asserts that "Obviously, it would be absurd to attempt the use of all the procedures ... but a reasonable selection can be made..." By and large, the researcher should attempt to gather data according to the objectives of the study. If the researcher tries to collect more than necessary data, then he/she will, naturally, be lost among the mass of unnecessary information. On the other hand, if he/she gathers less data, he/she will not gain enough insights towards the problem. A moderate amount of information is usually more preferable.

Certainly, the important issue that any researcher might encounter is the conflicting types of data that are gathered. Hutchinson and Waters (1987, p. 155) argue that "feedback from one party [e.g. learners or teachers] may contradict feedback from another." This is a type of problem that usually an outsider researcher might face because of his/her rather incomplete knowledge on the setting from which the data are collected. On the other hand, an insider researcher may fairly have thorough understanding of the context and tackle the issue more easily. In this regard, the researcher should try to gather more data and, of course, from different sources in order to gain more insight into the problem and into the contradictory data.

Data collection is a phase in the research cycle in which different type of information is gathered through different sources. Richards and Schmidt (2002, p. 142) believe that data are a collection of "information, evidence or facts" that are gathered in order to gain a "better understanding of a phenomenon." Seliger and Shohamy (1989) assert that there are two types of data collection procedures. First, data can be collected by means of a low degree of explicitness usually through informal and open interviews, observations and so forth. Second, it can be gathered by means of a high degree of explicitness usually through formal and structured questionnaires, interviews, observations, etc. However, they contend that in the latter procedure, the respondents are constrained to answer predetermined questions. The fact is that a researcher should attempt to gather both types of data in order to penetrate more deeply into the phenomenon. In this 
regard, Blaxter et al. (2006, p. 153) state that "data may be numerical, or may consist of words, or may be a combination of the two." To this end, Creswell (2003, p. 220) advises the researchers to be clear and specific about the type of data that they collect. That is, whether the data should be qualitative or quantitative.

Before attempting to collect data, the researcher should try to answer this question: "What type of data will need to be gathered - quantitative, qualitative, or both?" (Lynch, 1996, p. 6-7). It goes without saying that it mainly depends on the purpose of the evaluation and the research design. For instance, Elley (1989, p. 277) expresses that "if the objectives focus more on attitudes or interests, then suitable attitude scales, or observation techniques or diary reports will be more appropriate." On the whole, the most appropriate way of collecting data depends on evaluation question(s) and goals.

Lynch (1996: 7) stresses that if our primary question is "Are the students of this program making significant gains in their language abilities?" then we should use the quantitative design and gather quantitative data. These data can be obtained through administering some pretests before the start of the program and some posttests after the end of it. Therefore, the students' language ability and their achievements throughout the course can be measured through their scores before and after the program. However, if our primary question is: "How can we improve this program?" (ibid.) then we should use a qualitative design and collect qualitative data. In this process, data can be obtained through observations, interviews, and questionnaires. Palmer (1996) cautions that data collection and the research design should not disrupt the natural and normal schedule of a language learning-teaching process. Also, he emphasizes the practicality of the procedures used in the research design and the data gathering process. In the main, a study might avoid to administer and use tests because of its objectives. The reasons for avoiding tests as the source of data are as follows:

- A few number of the students attend private language institutes at the same time that they take part in an experimental study. Therefore, the results of the pretest and posttest data cannot be representative of the treatment and would consequently contaminate the results and their interpretations.

- Generally, constructing a uniform, fair, and identical test items for all the learners is rather difficult though not impossible. In evaluating the ESP programs at the Federal Universities of Brazil, Alderson and Scott (1996, p. 54) deliberately shunned using tests because "Appropriate standardized tests do not exist, and the variety of learning situations within the project is probably so great as to preclude the use of any common instruments in all participating universities."

- Certainly, process is more important than the product. The fact is that though most of the learners succeed in passing an instructional program with a pass mark, they can hardly use their knowledge practically in real situations. Therefore, test scores hardly reveal anything about the real and actual knowledge of the students.

- Some of the learners are quite interested in learning English and, therefore, they try to learn it at home through more reading, watching different English TV programs, or working with different educational soft wares and internet sites. So that, administering pretest and posttest to measure their achievement cannot indicate the effect of classroom learning and treatment. Consequently, the result of these tests might be questionable, because we do not know whether the high level of scores obtained by these students is related to classroom instruction and/or treatment or students' own selfstudy.

- It has been emphasized that the current proficiency tests assess the learners' competence rather than their performance. That is, the available tests measure the learners' passive rather than active knowledge. Also, these tests estimate the learners' word and sentence level knowledge and not beyond it. To this end, Lynch (1996, p. 164) attests that "The student improvement evidenced by the positivistic [experimental] analyses thus confirms the sentence-levelonly interpretation from the naturalistic data."

More importantly, Elley $(1989$, p. 277) is of the opinion that the available standardized tests have the following shortcomings:

- They are widely used and frequently too familiar ...

- They are often unsuitable culturally, by virtue of language or assumed background knowledge.

- The skills measured do not match those of the new program.

- They are too easy or too difficult ... at the beginning or end of the program.

- They are too costly or time-consuming for the purpose.

\section{MAKING SENSE OF DATA}

The researcher ought to opt for the type of data analysis based on the design that has already been selected and carried out in the data collection process. It should be emphasized that the main issue in the research process is the data analysis phase which "follows logically from the type of design chosen for the evaluation (Lynch, 1996, p. 7)". However, Creswell (1994, p. 153) claims that "The process of data analysis is eclectic; there is no right way." Nevertheless, this statement does not mean that the researcher is free to choose any method of analyzing data. It means that within the special design chosen for the study, the researcher might approach data analysis from different perspectives according to the research objectives, have necessary expertise in the data analysis and also have necessary facilities and resources at hand.

Data analysis does not take place only at one phase. An experienced researcher goes through the data at several stages and analyses them throughout the whole research process. To this end, Blaxter et al. (2006, p. 193) believe that 
"Analysis is an ongoing process which may occur throughout your research..." The purpose of this continuous data analysis is mainly to extract meaning from a pile of data. As Creswell (2003, p. 190) contends, it means "moving deeper and deeper into understanding the data, representing the data, and making an interpretation of the larger meaning of the data." In this regard, the researcher ought to find some appropriate ways of making sense out of a mass of data. Therefore, in order to interpret the data and present the results, the researcher should read through the data, analyze, categorize, condense and finally synthesize them (Seliger \& Shohamy, 1989). Obviously, data analysis demands that the researcher form some categories and at the same time make some necessary comparisons and contrasts. The researcher might face various types of contradictory data during this stage. He/She should make a wise and logical analysis according to the existing evidences. Creswell (1994, p. 153) argues that "the researcher be open to possibilities and see contrary or alternative explanations for the findings." Therefore, this stage is very important because it affects the results and conclusions of the study.

After the data have been collected through different procedures and from different sources, the researcher should find some appropriate ways of analyzing them. The quantitative data appears in numerical form and the qualitative data in a mass of words, sentences and texts. Brown (2001, p. 11) acknowledges that data analysis "rely fairly heavily on the human ability to find patterns in the data." Therefore, the researcher should find some proper ways of converting the data to patterns in order to make sense of them. The data which are obtained from the qualitative data are, in fact, voluminous and massive. Creswell (1994) holds that these bulky qualitative data need to be sorted into suitable categories. To this end, Lynch (1996) argues that data analysis is an iterative rather than a linear process. Therefore, he maintains that the primary steps in this process are to focus the study. That is, the researcher might create a thematic framework which consists of key evaluation questions that should be answered.

Miles and Huberman (1994, p. 56) contend that though the qualitative data are voluminous "than numbers, they can render more meaning, than numbers alone." Obviously, the qualitative data are more concrete, natural and understandable than the numerical data which are abstract, obscure and complex. Also, the qualitative data represent more elaborate information about the setting, situation under study, participants, instruments, procedures and so on. Therefore, in order to make sense of the data, the researcher should analyze them. The analysis is carried out so that necessary interpretations could be made. In this process, Blaxter et al. (2006) discuss that the data should be managed. That is, they should be sorted, reduced or summarized and finally reported. To manage the data more properly, Huberman and Miles (1994) offer three phases in which they can be analyzed. First, the data are reduced, then they are displayed, and finally some conclusions are drawn and verified. It is clear that the researcher should move step by step in order to make the data more understandable. The following six stages have been drawn upon Creswell's (2003) generic steps in analyzing data and are used in the analysis of the qualitative data. Thus, the researchers should.

- systematize and arrange the data.

- pore over the data.

- analyze and code the data.

- create categories, themes and patterns for analysis.

- think of ways of representing themes.

- interpret and make sense of data.

It is through data collection that the researcher has compiled a great deal of information through different means. These data need to be organized, coded, reduced and finally interpreted (Lynch, 1996). It goes without saying that data analysis is one of the demanding phases of any research process. If the researcher does not take adequate precautions, he/she may not be able to properly analyze the data and consequently interpret them. The following steps are drawn upon Blaxter et al.'s (2006) suggestions for data analysis.

- The researcher should try to manage the data through decreasing their size and scope, in this way they can be reported properly.

- The researcher should try to analyze the organized data through focusing on key aspects.

It can be said that the researcher should attempt to organize the data. Then, he/she should manage to peruse them so that to find some "patterns, categories, or themes" (Creswell, 1994, p. 154). After that he/she needs to reduce them "in advance to manageable dimensions" (Brown, 2001, p. 213). After reducing the data, the researcher needs to code them. These codes have to "be short enough to serve its purpose as a time-saving data marker" (lynch, 1996, p. 142). Also, the codes should be long enough so that they could be distinguished from other codes. After coding the data, the researcher needs to display the data in order to make necessary interpretations. Generally, the data are displayed in tables, matrices and various graphical forms. In this way, analyzing and interpreting them can become easier. Also, the displayed data allow the researcher to compare and contrast similarities and differences in the patterns and themes.

\section{FIRST STEP IN RESEARCH}

In fact, without piloting the instruments the researcher cannot ensure whether his/her design, data collection procedures and data analysis work in the real phase of the study. Pilot study is one of the important phases of any research endeavor. Dane (1990, p. 336) defines pilot study as "an abbreviated version of a research project in which the researcher practices or tests the procedures to be used in the subsequent full-scale project." Alderson (1996, p. 292) contends that "The instruments being used for the collection of data may themselves be opaque and therefore difficult 
for respondents to respond to." Therefore, all the data gathering instruments should be piloted and adjusted according to the necessities of the actual research situation. To this end, Blaxter et al. (2006, p. 137) argue that piloting allows the researcher to "see how they [techniques \& methods] work in practice, and, if necessary, modify your plans accordingly."

Seliger and Shohamy (1989) maintain that piloting is a kind of quality control in which the researcher has the opportunity to make any necessary changes and revisions. Furthermore, Brown (2001, p. 62) emphasizes that pilot study "can help you spot ambiguities, confusion, or other problems" and "to see what types of answers respondents produce." Therefore, a researcher can learn many useful things from data collection and data analysis process through the pilot study. As Blaxter et al. (2006, p. 41) express, the inquirer can at least get "an idea of the amount of time collecting data can take." Moreover, Brown (2001) believes that the pilot study should be carried out at similar situations to the real project and with the similar types of subjects. On the whole, the primary purposes of conducting the pilot study include the following points:

- to probe the reliability and validity of the research instruments;

- to check the acceptability and adequacy of the questionnaires and interview items;

- to modify and improve vague and ambiguous questions in the questionnaires and interview items;

- to discard the ineffective, inadequate and weak questions in the questionnaires and interview items;

- to practice interview skills and classroom observation process;

- to practice initial data collection and analysis processes.

\section{RESEARCH ETHICS}

Ethical issues should be considered from the planning stage to data collection through to data analysis to reporting the findings. Therefore, every researcher needs to take heed of the ethical issues at any stage of the research process. As Flick (2006, p. 49) contends, "You will be confronted with ethical issues at every step of research." In this regard, Burns (1999, p. 70) points out that "Ethical considerations are an important part of any research." The main issue in any research is to protect the rights and interests of the participants. However, the research ethics is somehow a complicated issue and we can hardly "find easy and very general solutions to the problems and dilemmas" (Flick, 2006, p. 52). Generally, in the field of research, ethics can be defined as being sensitive to the rights of others. Fraenkel and Wallen (2003, p. 56) state that "The term ethics refers to questions of right and wrong." On the whole, it can be inferred that to a large extent ethics is a matter of agreement among the researchers.

In order to conduct a study, the researchers should observe several essential issues. In this regard, Cohen and Manion (1994) mention some of these issues: privacy, anonymity, confidentiality, betrayal and deception. Privacy can be described as the private and personal life of people as opposed to their public life. Therefore, the researchers should not violate the private life of the respondents "through publication or other means of dissemination" (Merriam, 1998, p. 217). The personal information that the informants provide is sometimes sensitive and might be threatening. Thus, the researchers should observe the privacy of the information and not allow the respondents to be identified. To this end, the anonymity of the participants is very important. That is, the researchers should not reveal the identity of the respondents during and after the research process. The interviewees might be referred to by letters, numbers or pseudonyms and the questionnaires should not require the respondents to write their names. Therefore, the respondents must remain anonymous and the provided information should not reveal their identity.

Meanwhile, the researchers "need to guarantee participants complete confidentiality" (Flick, 2006, p. 49). That is, the respondents should "be assured that any data collected from or about them will be held in confidence" (Fraenkel \& Wallen, 2003, p. 59). One more issue is the betrayal. This term refers to occasions in which the confidential information disclosed by the subjects is made public. Therefore, the publication or dissemination of information may harm the participants and consequently embarrass them. Thus, the researchers should abstain from betraying the respondents. The final dilemma that Cohen and Manion (1994) mention is deception. Deception in research means that some researchers intentionally do not tell the whole truth to the participants. Some researchers conceal the true nature of the research and do not explain to the subjects the whole truth. These researchers try to obtain information or expose the informants to situations in which the subjects do not know the real objectives of the research.

In the main, there is hardly any ethical contention in the quantitative approaches to research because the data are in aggregate and numerical form (Merriam, 1998). However, in the qualitative approaches, there are many ethical controversies because these approaches directly deal with human beings, their opinions and behaviors. The degree of ethical problems is much more acute and tense in social, psychological and medical sciences than in the field of English Language Teaching (ELT). In the field of ELT, ethical problems may arise out of carelessness, negligence and the like. On the whole, the ethical issues may result from the nature of the problem under study and the methods that are used to investigate them. Each stage in the research has its own potential set of problems. For instance, in writing the research report we might come to a conclusion which "If your participants read these results, they may find it embarrassing to be compared with other people" (Flick, 2006, p. 50).

There are many sources of tension in research. Cohen and Manion (1994, p. 360) mention two sets of these sources: "First, a belief in the value of free scientific inquiry versus a belief in the dignity of individuals, second, the absolutist versus relativist positions." On the one hand, researchers try to obtain more information and knowledge, on the other 
hand, there is the issue of individuals' rights which should not be disregarded or violated. Also, there is the absolutists' camp which contends that there should be some set principles and rules which should guide the researchers in their research. However, the relativists hold that the ethical issues might arise during the research process and no set guidelines can determine what to do and what not to do.

The data collection phase has its own dilemmas. For example, participant observation is criticized because of "the questionable ethics of deceiving the other participants" (Merriam, 1998, p. 100). That is, the privacy of the students is threatened or they may disclose some information which they might regret it later. Also, some researchers might prefer the use of covert observation in order to reduce the effect of the observer in the classroom. However, Flick (2006, p. 219) expresses that "this is highly problematic with respect to research ethics." Also, collecting data during the interview encounter, the researcher should not ask questions which might hurt the respondents. The researcher should not try to argue with the subjects because his/her task "is first and foremost to gather data, not change people" (Patton, 1990 , p. 254). Moreover, the topics to be interviewed should not induce pain or bad memories on the part of the interviewee. Furthermore, the interviewers should not invade the interviewees' privacy nor should they coerce or persuade the respondents to reveal information that they do not intend to do so. In general, in conducting a study, the researchers should consider the subjects' rights as follows:

- The subjects should be free to choose to participate voluntarily in a research.

- The subjects can refuse to participate or withdraw from participation at any time without providing any reason.

- The subjects' anonymity should be considered.

- An instructor cannot require the students to participate in a research as a classroom project.

- The subjects should not be asked or directed to furnish the desired type of information.

Certainly, the researchers have some responsibilities which they should observe during and even after the conduct of the research as follows:

- The researchers should ensure the confidentiality of the data.

- The researchers should not deceive or betray the subjects.

- The researchers should obtain the informed consents of the participants.

- The researchers should explain the purpose of conducting the research to the informants.

- The researchers should honestly present a complete account of the research process.

- All the subjects must be treated equally.

- The researchers should think about the consequences of the study before conducting it.

- The results of the study should not harm or hurt participants and other stakeholders.

- The possible biases should be controlled and contained as far as possible.

- The researchers should respect the subjects and consider their needs and interests.

The researchers should obtain the informed consent of the participants before starting the data collection procedure. Flick's (2006, p. 46) definition of informed consent is: "the study's participants have agreed to partake on the basis of information given to them by the researchers." Therefore, the subjects decide whether to participate in the study based on their own choice. The researchers should completely explain to the subjects the procedures, possible risks and benefits of the research.

Overall, some ethical codes or principles have been developed in order to organize and regulate the researchers' behavior and make them aware of their responsibilities towards the subjects and their profession. Merriam (1998, p. 219) is of the opinion that "Professional codes and federal regulations deal with issues common to all social science research." In this regard, Flick (2006, p. 45) points out that "Codes of ethics are formulated to regulate the relations of researchers to the people and field they intend to study." To this end, Burns $(1999$, p. 71) presents three criteria for the ethical conduct of a research: "responsibility, confidentiality and negotiation." That is, the researchers should take responsibility of every single stage of the research, take into account the confidentiality of the obtained data, and negotiate every aspect of the research with the participants and the intended parties. In general, drawing upon Cohen and Manion (1994) the six-fold benefits of the codes of practice are as follows:

- It creates a sense of membership community for the researchers.

- It makes the researchers aware of their responsibilities to their subjects and the field.

- It makes the researchers to find other alternative and ethical ways of conducting the same research.

- It makes the researchers to prepare and organize themselves in any research situation.

- It prepares the researchers to face any unpredicted and unknown conditions.

- It creates a sense of disciplined behavior among the researchers.

It can be hardly pinpointed what is ethical and what is unethical, what is correct or what is incorrect research behavior. However, any research process should "produce some positive and identifiable benefits rather than simply be carried out for its own sake" (Murphy \& Dingwall, 2001, p. 339). Nevertheless, those benefits should not be obtained at the cost of deceiving, harming and disregarding the subjects' rights.

\section{RESEARCH ETHICS}

This article discussed and shed some fresh light on the five essential aspects of a research process. Any researcher who intends to conduct a study should have enough knowledge both in doing research and the problem at hand. The 
present article elaborated on the first issue. It was explained that, first of all, the design of the study should be identified. Then, the procedures of collecting data were expounded. After that, the different aspects of analyzing data were described. Next, it was emphasized that the researchers need to pilot their instruments in order to ensure that they can perform well in the real and actual phase of the study. Finally, the necessity of observing some rules and regulations of correct behavior on the part of the researchers was stressed in the ethical issues section. It is believed that executing a research requires a great deal of knowledge, expertise and time. Therefore, every research has its own peculiarities and specific characteristics which should be considered completely from the very beginning.

\section{REFERENCES}

[1] Alderson, J. C. (1996). Guidelines for the evaluation of language education. In J. C. Alderson \& A. Beretta (Eds.), Evaluating second language education. Cambridge: CUP, 274-304.

[2] Alderson, J. C. \& Scott, M. (1996). Insiders, outsiders and participatory evaluation. In J. C. Alderson \& A. Beretta (eds.), Evaluating second language education. Cambridge: CUP, 25-60.

[3] Blaxter, L., C. Hughes \& M. Tight. (2006). How to research. Berkshire: Open University Press.

[4] Brown, J. D. (1989). Language program evaluation: A synthesis of existing possibilities. In R.K. Johnson (ed.), The second language curriculum. Cambridge: CUP, 222-241.

[5] Brown, J. D. (1995). The elements of language curriculum: A systematic approach to program development. Boston, Mass.: Heinle \& Heinle Publishers.

[6] Brown, J. D. (2001). Using surveys in language programs. Cambridge: CUP.

[7] Burns, A. (1999). Collaborative action research for English language teachers. Cambridge: CUP.

[8] Burns, R. (2000). Introduction to research methods. London: Sage.

[9] Cohen, L. \& L. Manion. (1994). Research methods in education. Fourth ed. London: Routledge.

[10] Creswell, J. W. (1994). Research design: qualitative and quantitative approaches. Thousand Oaks, CA: Sage.

[11] Creswell, J. W. (2003). Research design: Qualitative, quantitative, and mixed methods approaches. Second ed. Thousand Oaks, CA: Sage.

[12] Dane, F. C. (1990). Research methods. California: Brooks/ Cole Publishing Company.

[13] Dudley-Evans, T. \& M. J. St John (2000). Developments in English for specific purposes: A multidisciplinary approach. Cambridge: CUP.

[14] Elley, W. B. (1989). Tailoring the evaluation to fit the context. In R. K. Johnson (ed.). The second language curriculum. Cambridge: CUP, 270-285.

[15] Flick, U. (2006). An introduction to qualitative research. London: Sage.

[16] Fraenkel, J. R. \& N. E. Wallen. (2003). How to design and evaluate research in education. Fifth ed. New York: McGraw-Hill.

[17] Huberman, A. M. \& M. B. Miles. (1994). Data management and analysis methods. In N. K. Denzin \& Y. S. Lincoln (eds.), Handbook of qualitative research. Thousand Oaks, CA: Sage Publications, 428-444.

[18] Hutchinson, T. \& A. Waters. (1987). English for specific purposes: A learning-centered approach. Cambridge: CUP.

[19] Long, M. H. (1984). Process and product in ESL program evaluation. TESOL Quarterly, 18.3, 409-425.

[20] Lynch, B. K. (1996). Language program evaluation: Theory and practice. Cambridge: CUP.

[21] Merriam, S. B. (1998). Qualitative research and case study applications in education. San Francisco: Jossey-Bass.

[22] Miles, M. B. \& A. M. Huberman. (1984). Qualitative data analysis: A sourcebook of new methods. Beverly Hills, CA: Sage.

[23] Miles, M. B. \& Huberman, A. M. (eds.). (1994). Qualitative data analysis. Second ed. Thousand Oaks, CA: Sage.

[24] Murphy, D. F. (1985). Evaluation in language teaching: Assessment, accountability and awareness. In J. C. Alderson (ed.), Evaluation. Oxford: Pergamon Press, 1-17.

[25] Murphy, E. \& R. Dingwall. (2001). The ethics of ethnography. In Atkinson, P., Coffey, A., Delamont, S., Lofland, J. \& Lofland, L. (eds.), Handbook of ethnography. London: Sage, 339-351.

[26] Nunan, D. (1999). Research methods in language learning. Eighth printing. Cambridge: CUP.

[27] Palmer, A. (1996). Issues in evaluating input-based language teaching programs. In J. C. Alderson \& A. Beretta (Eds.) Evaluating second language education. Cambridge: CUP, 141-164.

[28] Patton, M. Q. (1990). Qualitative evaluation and research methods. Second ed. Newbury Park, CA: Sage.

[29] Richards, J. C. \& R. Schmidt. (2002). Longman dictionary of language teaching and applied linguistics. London: Longman.

[30] Seliger, H. W. \& E. Shohamy. (1989). Second language research methods. Oxford: OUP.

[31] Slimani, A. (1996). Evaluation of classroom interaction. In J. C. Alderson \& A. Beretta (eds.), Evaluating second language education. Cambridge: CUP, 197-220.

Mohammad Zohrabi is an assistant professor and has taught various courses at the University of Tabriz, Iran. He has published 4 books: A Dictionary of Research Terms in Applied Linguistics, A Dictionary of Language and Linguistics, Reading English in Action, and Active Reading Comprehension. His research interests include: program evaluation, material writing and evaluation, first and second language acquisition, teaching reading and writing skills, English for academic purposes, English for general purposes, and English for specific purposes. 